\title{
Retrospective lifetime dietary patterns predict cognitive performance in community-dwelling older Australians
}

\author{
Diane E. Hosking ${ }^{1}$, Ted Nettelbeck ${ }^{2}$, Carlene Wilson ${ }^{1} \dagger$ and Vanessa Danthiir ${ }^{1 *}$ \\ ${ }^{1}$ Commonwealth Scientific and Industrial Research Organisation, Animal, Food and Health Sciences, \\ Preventative Health Research Flagship, PO Box 10041, Adelaide, SA 5000, Australia \\ ${ }^{2}$ School of Psychology, University of Adelaide, Adelaide, SA, Australia \\ (Submitted 20 June 2013 - Final revision received 27 November 2013 - Accepted 4 February 2014 - First published online 8 April 2014)
}

\begin{abstract}
Dietary intake is a modifiable exposure that may have an impact on cognitive outcomes in older age. The long-term aetiology of cognitive decline and dementia, however, suggests that the relevance of dietary intake extends across the lifetime. In the present study, we tested whether retrospective dietary patterns from the life periods of childhood, early adulthood, adulthood and middle age predicted cognitive performance in a cognitively healthy sample of 352 older Australian adults $>65$ years. Participants completed the Lifetime Diet Questionnaire and a battery of cognitive tests designed to comprehensively assess multiple cognitive domains. In separate regression models, lifetime dietary patterns were the predictors of cognitive factor scores representing ten constructs derived by confirmatory factor analysis of the cognitive test battery. All regression models were progressively adjusted for the potential confounders of current diet, age, sex, years of education, English as native language, smoking history, income level, apoE $\varepsilon 4$ status, physical activity, other past dietary patterns and health-related variables. In the adjusted models, lifetime dietary patterns predicted cognitive performance in this sample of older adults. In models additionally adjusted for intake from the other life periods and mechanistic health-related variables, dietary patterns from the childhood period alone reached significance. Higher consumption of the 'coffee and high-sugar, high-fat extras' pattern predicted poorer performance on simple/choice reaction time, working memory, retrieval fluency, short-term memory and reasoning. The 'vegetable and non-processed' pattern negatively predicted simple/choice reaction time, and the 'traditional Australian' pattern positively predicted perceptual speed and retrieval fluency. Identifying early-life dietary antecedents of older-age cognitive performance contributes to formulating strategies for delaying or preventing cognitive decline.
\end{abstract}

Key words: Lifetime diet: Retrospective dietary patterns: Cognition: Ageing

Lifestyle approaches to delaying cognitive decline and the incidence of dementia are of considerable interest; delaying disease onset and progression by 1 year would result in approximately $9 \cdot 2$ million fewer cases worldwide by $2050^{(1)}$. Dietary intake is a modifiable exposure that potentially influences cognitive status in older age via nutritional mechanisms that contribute to brain health and functioning ${ }^{(2)}$. Dietary intake is also implicated in the aetiologies of CVD, diabetes and stroke, all of which are risk factors for unfavourable later-life cognitive outcomes ${ }^{(3)}$.

Substantial evidence is accruing for both protective and detrimental effects of dietary patterns on older-age cognition $^{(4)}$. The Mediterranean diet, together with dietary patterns that share a similar profile (so those rich in vegetables, fruits, grains and fish), have been reported to be protective against the risk of dementia and cognitive decline ${ }^{(5-10)}$, and in cross-sectional studies, they have been shown to be associated with better cognitive performance ${ }^{(10-15)}$. Conversely, dietary patterns defined by processed foods high in saturated fats and sugar predict poorer cognitive functioning ${ }^{(12,16)}$.

A major challenge when determining dietary strategies for the maintenance of cognitive health is the appropriate timing of any intervention. A large portion of the intellectual variability that exists between older people is present by childhood $^{(17)}$, and cognitive ageing itself begins during early adulthood $^{(18)}$. The brain pathology that underpins dementia accumulates over many years before clinical symptoms become apparent ${ }^{(19)}$, and is evident in mid-life for those that are genetically predisposed to Alzheimer's disease ${ }^{(20)}$. Therefore, the impact of diet on older-age cognition is likely to be

Abbreviations: EPOCH, Older People, Omega-3 and Cognitive Health; LDQ, Lifetime Diet Questionnaire.

* Corresponding author: V. Danthiir, email vanessa.danthiir@csiro.au

†Present address: Centre for Innovation in Cancer, Flinders University, Cancer Council South Australia, Adelaide, SA, Australia 
a function of intake over the lifetime, with possible sensitive periods when dietary exposures are particularly salient ${ }^{(21)}$.

Only one known study has examined dietary patterns from an earlier life period as predictors of older-age cognitive function. In the SU.VI.MAX 2 (Supplementation with Antioxidant Vitamins and Minerals 2) ${ }^{(22)}$ study, a 'healthy' pattern consumed at mid-life, defined by fruit, whole grains, vegetables, and negatively correlated with meat and poultry, was associated with better cognitive scores 13 years later ${ }^{(23)}$. Currently, however, there are no cohort studies with comprehensive dietary data over multiple decades to assess the 'life course approach' to cognitive ageing ${ }^{(24)}$ in the context of dietary intake.

Cognitively healthy older people can recall general consumption frequencies for individual foods, and food groups, over multiple life periods with reasonable reliability ${ }^{(25)}$. Additionally, dietary recall of earlier intake has been demonstrated to capture dietary change, and to be associated with relevant demographic and health outcomes ${ }^{(26)}$. Lifetime dietary recall, therefore, offers a novel and practical solution to examining dietary intake and older-age cognition within a life-course framework.

The present study examined recalled dietary patterns from the life periods of childhood, early adulthood, adulthood and middle age as predictors of comprehensively measured cognitive outcomes in an older sample of cognitively healthy adults.

\section{Methods \\ Design and participants}

Participants were a subsample of the EPOCH (Older People, Omega-3 and Cognitive Health) trial; an 18-month doubleblind, randomised, controlled trial of $n-3$ fish oil on cognitive functioning in a community-dwelling population of older adults in Adelaide, South Australia. Recruitment commenced in June 2007 and baseline assessment was completed by December 2008. A detailed account of the study's design and measures can be found in the study protocol ${ }^{(27)}$. Participants were older adults aged 65-90 years, who had a score $>22 / 27$ on a modified telephone-administered Mini Mental State Examination ${ }^{(28)}$, and lived in the greater metropolitan area of Adelaide, South Australia. Of the 390 eligible EPOCH trial members, $352(90 \%)$ contributed lifetime dietary data. The study was conducted in compliance with the Declaration of Helsinki and followed Good Clinical Research Practice Guidelines. All experimental procedures were approved by the Human Research Ethics Committee of CSIRO Animal, Food and Health Sciences. Informed consent was obtained from all participants. The present study reports the cross-sectional relationships between dietary patterns, assessed by recall of dietary intake across the lifetime, and baseline cognitive measures from the EPOCH trial ${ }^{(27)}$. All analyses were adjusted for demographic, lifestyle and physiological variables.

\section{Procedure}

Participants completed multiple questionnaires to assess demographic, lifestyle, health and well-being factors prior to the cognitive testing sessions held at the study centre (CSIRO Animal, Food and Health Sciences). The sessions were conducted in groups of up to seven people. A fasted venous blood sample was collected, together with measurements of height, weight and blood pressure. After consuming a standardised breakfast, participants undertook the cognitive test battery that was administered by two trained research staff. The battery was divided into computer-based tasks and pencil and paper-based tasks, and took approximately $4 \mathrm{~h}$ to complete, with 10 min breaks given every hour.

At 3 months of post-baseline assessment, participants collected their quarterly supply of study capsules from the study centre and provided notification of any medication changes. During this visit, they were given the opportunity to complete the self-administered Lifetime Diet Questionnaire (LDQ) $)^{(25)}$ at home and return it to the study centre by post.

\section{Lifetime diet}

Lifetime diet was assessed by the $\mathrm{LDQ}^{(25)}$, a measure of historical dietary intake covering all life periods from childhood to older age. The questionnaire's rationale and design have been detailed previously, together with its reproducibility in an equivalent population: average reproducibility across the life periods was 0.81 and the average weighted $\kappa$ was 0.49 for recall agreement between food groups ${ }^{(25)}$. Although the LDQ has not been validated against dietary records, support for the questionnaire's validity was demonstrated by the plausible associations found between early-life dietary intake, as measured by the LDQ, and both demographic and late-life cardiovascular outcomes ${ }^{(26)}$. A brief description of the measuring tool is as follows. The questionnaire distinguishes between the life periods of childhood (5-18 years), early adulthood (19-30 years), adulthood (31-45 years) and middle age (46-60 years), and uses a nonquantitative approach; response options are on a four-point scale: 'rarely/never'; 'two to three times a month'; 'two to three times a week'; 'daily'. The food groups and their items remain the same for each life period with exceptions being food items that were unlikely to have been consumed during a given period. The number of items ranged from seventy-four in childhood to seventy-nine in early adulthood, with adulthood and middle age each having seventy-eight items. Physical activity levels across all life periods were also assessed as a proxy measure for energy expenditure. Level of physical activity associated with occupation was categorised as 'little', 'some', 'frequent' or 'heavy and frequent'. All other physical activities were assessed as the frequency per week of (any or all) vigorous, moderate and light physical activity.

The variables representing lifetime dietary intake in the present study were dietary pattern factor scores from each distinct life period of the LDQ. The dietary pattern analysis of the LDQ has been fully described elsewhere ${ }^{(26)}$, so it is only briefly described here. Exploratory factor analysis for ordinal variables was used to extract dietary factors from each life period of the LDQ using M-plus ${ }^{(29)}$. Each dietary factor was 
defined by the individual food items with the highest loadings on $\mathrm{it}^{(30)}$. In addition, these factors explained the following percentages of the shared variance among the questionnaire items for each life period: $31.6 \%$ in childhood; $31.87 \%$ in early adulthood; $26.93 \%$ in adulthood; $26 \cdot 12 \%$ in middle age. The extracted dietary factors with their ten highestloading food items are presented in Table 1. These items do not fully define the factors; the tables of all individual food items and their loadings $>0.3$ for each factor have been fully reported previously ${ }^{(26)}$.

The naming of the dietary factors indicated the foods, or types of foods, that defined the factor or (in the case of 'traditional Australian' or 'non-traditional Australian') differentiated between the types of diet based on their social determinants ${ }^{(31)}$. Dietary pattern scores were calculated by weighting the individuals' frequency of consumption for each item by its loading on each of the dietary patterns and then summing the items ${ }^{(32)}$. These scores were used as predictor variables in the present study; a higher dietary pattern score equated to greater consumption with the exception of the childhood 'coffee and highsugar, high-fat extras' pattern. For this pattern, all food item loadings were negative, so its dietary pattern score was reverse coded.

\section{Cognitive outcomes}

The cognitive test battery used in the EPOCH trial took a comprehensive approach to cognitive functioning with the inclusion of tasks to assess multiple cognitive domains. In particular, a number of cognitive tests were chosen as indicators of cognitive speed constructs ${ }^{(33)}$, given that cognitive speed is a sensitive indicator, vulnerable to the effects of ageing, and arguably fundamental to higher-order abilities ${ }^{(34)}$. The design, composition and statistical analyses of this test battery have been fully described and reported in the EPOCH trial protocol ${ }^{(27)}$. In total, six speed-based and four accuracy-based cognitive constructs were derived from two confirmatory factor analytical models of twenty-six tests. These constructs were found to be empirically distinct and the tests that defined them are listed as follows:

\section{Speed-based constructs.}

(1) Perceptual speed (Finding As, Number Comparison, Digit-Symbol Coding)

(2) Simple/choice reaction time (Simple, Two-choice, Fourchoice)

(3) Speed of memory scanning (Number and Letter Memory Scanning)

(4) Reasoning speed (Number and Letter Odd-Man-Out)

Table 1. Dietary patterns extracted from the Lifetime Diet Questionnaire (LDQ) and the ten highest-loading food items on each pattern

\begin{tabular}{|c|c|}
\hline Lifetime dietary patterns & $\begin{array}{l}\text { Ten highest-loading food items on dietary } \\
\text { patterns extracted from the LDQ }\end{array}$ \\
\hline CHD 'vegetable and non-processed' & $\begin{array}{l}\text { Parsnip, cruciferous vegetables, rhubarb, beetroot, carrots, } \\
\text { plums, lentils/beans, oats, pears, berries }\end{array}$ \\
\hline CHD 'traditional Australian' & $\begin{array}{l}\text { White grapes, red grapes, apricots/peaches, citrus } \\
\text { fruit, Vegemite, melon, pumpkin, bananas, butter, } \\
\text { cream }\end{array}$ \\
\hline CHD 'coffee and high-sugar, high-fat extras' & $\begin{array}{l}\text { Sweet coffee, white coffee, snack food, } \\
\text { soft drinks, chocolate, nuts, cherries, chicken, } \\
\text { ice cream, parsley }\end{array}$ \\
\hline EAD 'vegetable' & $\begin{array}{l}\text { Carrots, green beans, tomatoes, beetroot, lettuce, } \\
\text { potatoes, cruciferous vegetables, parsnip, rhubarb, pumpkin }\end{array}$ \\
\hline EAD 'traditional Australian' & $\begin{array}{l}\text { White grapes, red grapes, apricots/peaches, ice } \\
\text { cream, soft drink, melon, citrus fruit, } \\
\text { nuts, snack food, bananas }\end{array}$ \\
\hline EAD 'non-traditional Australian' & $\begin{array}{l}\text { Multi-grain bread, whole-grain bread, red wine, } \\
\text { herbs, margarine, parsley, other wine, chicken, } \\
\text { vegetable oil, white rice }\end{array}$ \\
\hline$A D$ 'fruit and vegetable' & $\begin{array}{l}\text { Carrots, apples, plums, beetroot, apricots/peaches, citrus } \\
\text { fruit, tomatoes, green beans, bananas, white grapes }\end{array}$ \\
\hline AD 'non-traditional Australian’ & $\begin{array}{l}\text { Herbs, peppers, red wine, parsley, olive } \\
\text { oil, yogurt, seafood, other wine, red } \\
\text { grapes, chicken }\end{array}$ \\
\hline$A D$ 'processed, high-sugar and high-fat' & $\begin{array}{l}\text { Soft drinks, take-away food, ice cream, } \\
\text { white bread, sweet coffee, sweet tea, } \\
\text { snack food, chocolate, sausages, desserts }\end{array}$ \\
\hline MAGE 'fruit, vegetable and non-processed' & $\begin{array}{l}\text { Apricots/peaches, plums, cherries, pears, apples, citrus } \\
\text { fruit, lettuce, white grapes, bananas, berries }\end{array}$ \\
\hline MAGE 'non-traditional Australian' & $\begin{array}{l}\text { Herbs, olives, parsley, seafood, olive oil, } \\
\text { red wine, peppers, onions, other wine, } \\
\text { red grapes }\end{array}$ \\
\hline MAGE 'processed, high-sugar and high-fat' & $\begin{array}{l}\text { Soft drinks, ice cream, desserts, snack } \\
\text { food, sausages, white bread, cream, take-away } \\
\text { food, chocolate, red meat }\end{array}$ \\
\hline
\end{tabular}

CHD, childhood; EAD, early adulthood; AD, adulthood; MAGE, middle age. 
(5) Inhibition (Simon task, Spatial and Colour Stroop)

(6) Psychomotor speed (Simple, Up and Diagonal Movement Tasks)

\section{Accuracy-based constructs.}

(1) Working memory (Operation Span, Counting Span)

(2) Retrieval fluency (Word Endings, Categories)

(3) Short-term memory (Face Recognition, Word List Recall, Paired Associates)

(4) Reasoning (Raven's Standard Progressive Matrices, Letter Sets, Everyday Problem Solving)

Constructs derived by the confirmatory factor analysis exclude error variance and test-specific variance, and so represent only the shared variance between the two or more tests that define them. Construct validity and the reliability of assessment is thereby increased ${ }^{(27)}$. Factor scores were estimated for the cognitive constructs in the same manner as for the dietary patterns; scores on each of the cognitive test variables were weighted by their loadings on the relevant factor and then summed.

\section{Other variables}

The acknowledged correlates of older-age cognitive status were assessed, in addition to lifestyle or health and wellbeing outcomes that could plausibly be related to lifetime dietary patterns. These measures were obtained during the course of the EPOCH trial. The full details for these measures have been described in the trial protocol ${ }^{(27)}$; however, the variables used in the present analyses are listed below.

Demographic variables. Demographic variables were as follows: age; sex; years of education (school, tertiary and vocational); native language (a dichotomised variable representing English or other); a four-level parental income variable (constructed from parental occupation); current income level (a nineteen-category variable following the Australian Census 2006).

Health/lifestyle variables. Health/lifestyle variables included the following: years of smoking (calculated as pack-years); BMI ( $\left.\mathrm{kg} / \mathrm{m}^{2}\right)$; systolic blood pressure; depressive symptoms (assessed by the Centre for Epidemiological Studies Depression Scale $\left.{ }^{(35)}\right)$; medication use for cardiac conditions, hypertension, cholesterol levels and depression (dichotomous variables representing usage or non-usage); past physical activity (assessed by the $\mathrm{LDQ}^{(25)}$ ); current physical activity (assessed by the Yale Physical Activity Scale ${ }^{(36)}$ ).

Blood-based markers. Blood-based markers were as follows: apoE genotype (dichotomised as the presence or absence of the apoE $\varepsilon 4$ allele); plasma homocysteine; LDL-cholesterol; HDL-cholesterol.

Present and past dietary covariates. Recall of past dietary intake is known to be confounded and biased by current dietary measures ${ }^{(37)}$; therefore, three exploratory factor analysis-derived pattern scores from the baseline response frequencies of the Dietary Questionnaire for Epidemiological Studies ${ }^{(38)}$ were included as covariates. In addition, all twelve past dietary factors were interdependent, so in order to allow the identification of any unique contribution by a past dietary pattern, principal component analyses were employed to create a set of four unrelated past dietary variables that accounted for the shared variance among all the other past dietary patterns (not including the pattern focused on as the main predictor in each model). Details of both the present and past dietary pattern analyses have been reported previously ${ }^{(26)}$.

\section{Missing data}

For the LDQ, those who had whole life periods ( $n$ 9) or $>80 \%$ of responses missing across any life periods ( $n$ 3) were excluded from missing value analysis. The remaining missing data in the LDQ were of two types: item non-response (mean per person 6.43 (SD 10.79)) and multiple consumption frequencies reported for a food item (mean per person 1.06 (SD 0.55)). The explanation and rationale for the treatment of missing data in the LDQ have been described previously ${ }^{(26)}$; all missing responses were imputed using the EM (Expectation Maximization) ${ }^{(39)}$ procedure implemented with Missing Value Analysis in the SPSS for Windows statistical package version 17.0.1 (SPSS, Inc.). There were minimal missing values for the cognitive data, but these were estimated by the FullInformation Maximum-Likelihood method as part of the confirmatory factor analysis of the test battery ${ }^{(27)}$. The small proportion of values missing on the continuous covariate data was estimated using the EM procedure; categorical data with missing values were dealt with by pairwise deletion in the analyses.

\section{Regression models}

Multiple linear regression models were used to examine the prediction of baseline cognitive performance by individual dietary patterns extracted from the life periods of the LDQ. Separate models were performed with each cognitive factor score as the outcome variable predicted by each of the dietary pattern scores separately. The models were progressively adjusted for three blocks of covariate entries described below.

Block 1. Block 1 was adjusted for age, sex, years of education, smoking history, income level (parents' income for the two earlier life periods and current income for the two later life periods), English as native language, presence of the apoE $\varepsilon 4$ allele and current dietary intake.

Block 2. In block 2, the four-component scores represented past dietary intake excluding the predictor period of interest.

Block 3. Block 3 was adjusted for systolic blood pressure, HDL-cholesterol, LDL-cholesterol, homocysteine, CES-D score, and medication use for cardiac conditions, hypertension, cholesterol levels and depression. Variables in this block were considered as potential mechanisms for the associations between lifetime dietary patterns and cognitive outcomes.

In total, there were twenty-four predictors in each model. With a total sample size of 352 and $\alpha=0.05$ (two-tailed), there was a power of 0.8 to detect an $f^{2}$ effect size of 0.023 for the contribution of a single predictor (i.e. the dietary pattern) ${ }^{(40)}$. 
Examination of the regression diagnostics in preliminary models demonstrated no violation of assumptions; in particular, high multicollinearity was not apparent among the dietary predictors (past and present), so the contribution of individual dietary patterns could be feasibly evaluated.

Alternative analyses were carried out without adjusting for current dietary intake; previous findings have indicated that current dietary patterns accounted for incrementally increasing amounts of variance in past dietary patterns across the lifetime ${ }^{(26)}$, so in later life periods, it was possible that past dietary effects were being confounded by current dietary intake.

\section{Results}

Descriptive statistics for the EPOCH sample are presented in Table 2.

A total of 352 individuals $(53.7 \%$ female $)$ completed the LDQ, with an age range of 65-91 years (mean 73.12 (SD 5.47)). Of the study participants, $26 \cdot 4 \%$ of men and $37.6 \%$ of women completed schooling to year 10 and $22.7 \%$ of men and $21.8 \%$ of women completed schooling to year 12. A bachelor's degree was held by $8.2 \%$ of the sample. Mann-Whitney non-parametric tests demonstrated that there were no significant differences between the LDQ participants and non-participants from the EPOCH cohort in any of the ten cognitive constructs or in terms of age ( $U=6714 \cdot 00, P=0 \cdot 823$ ), level of education $(U=6378 \cdot 00$, $P=0.454)$ and the baseline Mini Mental State Examination score $(U=6582 \cdot 50, P=0.891)$.

Table 2. Descriptive statistics for the EPOCH (Older People, Omega-3 and Cognitive Health) sample who undertook the Lifetime Diet Questionnaire

(Mean values and standard deviations)

\begin{tabular}{|c|c|c|}
\hline Variables & Mean & SD \\
\hline Age (years) & $73 \cdot 12$ & 5.47 \\
\hline Years of education & 12.91 & $4 \cdot 16$ \\
\hline MMSE & 28.71 & $1 \cdot 32$ \\
\hline Smoking history (pack-years) ${ }^{\star}(2) \dagger$ & 9.83 & $17 \cdot 77$ \\
\hline $\mathrm{BMI}\left(\mathrm{kg} / \mathrm{m}^{2}\right)$ & $27 \cdot 27$ & $4 \cdot 29$ \\
\hline Systolic blood pressure $(\mathrm{mmHg})(1) \dagger$ & $136 \cdot 83$ & $16 \cdot 48$ \\
\hline HDL-cholesterol (mmol/l) (2)† & 1.39 & 0.36 \\
\hline LDL-cholesterol (mmol/l) (2)† & $3 \cdot 16$ & 0.86 \\
\hline Plasma homocysteine $(\mu \mathrm{mol} / \mathrm{l})(5) \dagger$ & $10 \cdot 66$ & 3.23 \\
\hline Medication use & \multicolumn{2}{|c|}{$\%$ of sample } \\
\hline Cardiac medication & \multicolumn{2}{|c|}{$26 \cdot 4$} \\
\hline Cholesterol medication & \multicolumn{2}{|c|}{25.9} \\
\hline Hypertensive medication & \multicolumn{2}{|c|}{$42 \cdot 3$} \\
\hline Depressive medication & \multicolumn{2}{|c|}{$6 \cdot 5$} \\
\hline Sex (female) & \multicolumn{2}{|c|}{$53 \cdot 7$} \\
\hline ApoE $\varepsilon 4$ allele carrier (1)† & \multicolumn{2}{|c|}{$24 \cdot 8$} \\
\hline \multicolumn{3}{|l|}{ Current income } \\
\hline$>$ Australian median for $>65$ years $(24) \dagger$ & \multicolumn{2}{|c|}{$44 \cdot 4$} \\
\hline English-speaking & \multicolumn{2}{|c|}{$95 \cdot 7$} \\
\hline \multicolumn{3}{|l|}{ Parents' income $(20) \dagger$} \\
\hline Low & \multicolumn{2}{|c|}{21} \\
\hline Medium/high & \multicolumn{2}{|c|}{$73 \cdot 3$} \\
\hline
\end{tabular}

MMSE, Mini Mental State Examination.

${ }^{*}$ Pack-years $=($ cigarettes $/ \mathrm{d} \times$ years of smoking $) / 20$.

† Missing values.

\section{Individual lifetime dietary patterns as predictors of cognitive constructs}

Tables 3 and 4 present the standardised regression weights and their $P$ values for the relationships between each lifetime dietary pattern and the cognitive factors. After adjustment for current dietary intake, demographic and lifestyle variables, in addition to the presence of the apoE $\varepsilon 4$ allele (model 1), the childhood 'vegetable and non-processed' pattern negatively predicted perceptual speed, simple/choice reaction time and working memory. The childhood 'coffee and highsugar, high-fat extras' pattern negatively predicted simple/ choice reaction time, and strongly and significantly negatively predicted all accuracy-based constructs. The remainder of significant associations for model 1 were for the accuracy-based rather than the speed-based constructs. Working memory was negatively predicted by the early-adulthood 'vegetable' and 'non-traditional' patterns and the middle-age 'fruit, vegetable and non-processed' pattern. Short-term memory was negatively predicted by the 'non-traditional Australian' pattern in both early adulthood and adulthood. When current dietary patterns were excluded as covariates, no additional associations were found between any of the life periods and the cognitive outcomes (results not shown).

Model 2 additionally controlled for the variance shared between the dietary pattern of interest and the other lifetime patterns. Significant negative associations remained between the childhood 'vegetable and non-processed' pattern and simple/choice reaction time, and between the childhood 'coffee and high-sugar, high-fat extras' pattern and all accuracy-based constructs. In this model, two additional relationships reached significance; the childhood 'traditional Australian' pattern positively predicted perceptual speed and retrieval fluency. As a final step, the mechanistic health-related variables were included in all models. The childhood 'traditional Australian' pattern remained positively associated with retrieval fluency and the childhood 'coffee and highsugar, high-fat extras' pattern remained negatively associated with all the accuracy-based constructs, and reached significance for simple/choice reaction time. The strength of significant associations between model 2 and model 3 changed very little. No other associations remained significant or reached significance.

\section{Discussion}

In models adjusted for relevant demographic covariates, the apoE $\varepsilon 4$ allele and current dietary intake, lifetime dietary patterns predicted cognitive performance in normally functioning older adults. In models additionally adjusted for all other dietary patterns, the associations that remained were for the period of childhood only, with all the three patterns from this period demonstrating associations with cognitive performance in older age.

Adequate nutrition is essential for cognitive development in childhood $^{(41-43)}$, and cognitive ability in childhood is strongly related to cognitive ability across the lifetime ${ }^{(17)}$. The period of childhood for these participants spanned varying periods of 
Table 3. Lifetime dietary factors as predictors of the speed-based constructs* (Standardised regression weights $(\beta)$ with their $P$ values)

\begin{tabular}{|c|c|c|c|c|c|c|c|c|c|c|c|c|c|}
\hline \multirow[b]{2}{*}{ Lifetime dietary patterns } & & \multicolumn{2}{|c|}{ Perceptual speed } & \multicolumn{2}{|c|}{$\begin{array}{l}\text { Psychomotor } \\
\text { speed }\end{array}$} & \multicolumn{2}{|c|}{ Inhibition† } & \multicolumn{2}{|c|}{$\begin{array}{l}\text { Simple/choice } \\
\text { reaction time }\end{array}$} & \multicolumn{2}{|c|}{ Reasoning speed } & \multicolumn{2}{|c|}{ Memory scanning } \\
\hline & & $\beta$ & $P$ & $\beta$ & $P$ & $\beta$ & $P$ & $\beta$ & $P$ & $\beta$ & $P$ & $\beta$ & $P$ \\
\hline \multirow[t]{3}{*}{ CHD 'vegetable and non-processed' } & Model 1 & -0.126 & 0.023 & -0.093 & 0.098 & -0.090 & 0.123 & -0.124 & 0.028 & -0.027 & 0.627 & -0.032 & 0.581 \\
\hline & Model 2 & -0.137 & 0.057 & -0.111 & 0.130 & -0.103 & 0.172 & -0.152 & 0.037 & -0.029 & 0.696 & -0.061 & 0.414 \\
\hline & Model 3 & -0.091 & 0.205 & -0.061 & 0.411 & -0.096 & 0.212 & -0.122 & 0.104 & -0.017 & 0.827 & -0.019 & 0.806 \\
\hline \multirow[t]{3}{*}{ CHD 'traditional Australian' } & Model 1 & 0.015 & 0.784 & -0.012 & 0.824 & -0.076 & $0 \cdot 181$ & 0.014 & 0.807 & -0.005 & 0.933 & 0.057 & 0.318 \\
\hline & Model 2 & $0 \cdot 151$ & 0.038 & 0.044 & 0.551 & -0.086 & 0.263 & 0.138 & 0.062 & 0.025 & 0.741 & 0.138 & 0.069 \\
\hline & Model 3 & 0.142 & 0.053 & 0.035 & 0.645 & -0.088 & 0.264 & 0.122 & 0.109 & -0.018 & 0.818 & 0.125 & 0.114 \\
\hline \multirow[t]{3}{*}{ CHD 'coffee and high-sugar, high-fat extras' } & Model 1 & -0.050 & 0.362 & 0.010 & 0.857 & -0.022 & 0.706 & -0.111 & 0.046 & -0.063 & 0.251 & -0.019 & 0.741 \\
\hline & Model 2 & -0.011 & 0.866 & 0.067 & 0.325 & -0.002 & 0.978 & -0.132 & 0.055 & -0.097 & 0.156 & -0.028 & 0.688 \\
\hline & Model 3 & -0.033 & 0.619 & 0.044 & 0.514 & -0.010 & 0.887 & -0.150 & 0.030 & -0.099 & 0.155 & -0.046 & 0.522 \\
\hline \multirow[t]{3}{*}{ EAD 'vegetable' } & Model 1 & -0.098 & 0.092 & -0.045 & 0.446 & -0.044 & 0.474 & -0.033 & 0.579 & -0.001 & 0.983 & -0.021 & 0.733 \\
\hline & Model 2 & -0.071 & 0.356 & -0.011 & 0.892 & -0.032 & 0.685 & 0.015 & 0.853 & 0.009 & 0.909 & -0.045 & 0.429 \\
\hline & Model 3 & -0.062 & 0.414 & 0.003 & 0.973 & -0.031 & 0.702 & 0.029 & 0.714 & 0.020 & 0.801 & -0.031 & 0.701 \\
\hline \multirow[t]{3}{*}{ EAD 'traditional Australian’ } & Model 1 & -0.040 & 0.486 & -0.058 & 0.303 & 0.035 & 0.556 & -0.020 & 0.729 & 0.010 & 0.863 & -0.006 & 0.918 \\
\hline & Model 2 & 0.051 & 0.563 & -0.076 & 0.391 & 0.128 & 0.166 & 0.062 & 0.494 & 0.046 & 0.607 & -0.025 & 0.788 \\
\hline & Model 3 & 0.015 & 0.866 & -0.121 & 0.178 & 0.110 & 0.237 & 0.026 & 0.775 & 0.013 & 0.892 & -0.067 & 0.478 \\
\hline \multirow{3}{*}{ EAD ‘non-traditional Australian’ } & Model 1 & -0.125 & 0.040 & -0.094 & 0.122 & -0.018 & 0.714 & -0.103 & 0.096 & -0.018 & 0.772 & -0.030 & 0.630 \\
\hline & Model 2 & -0.104 & 0.152 & -0.091 & 0.211 & 0.004 & 0.958 & -0.082 & 0.267 & -0.006 & 0.936 & -0.056 & 0.458 \\
\hline & Model 3 & -0.052 & 0.466 & -0.057 & 0.440 & 0.033 & 0.667 & -0.038 & 0.612 & 0.012 & 0.869 & -0.021 & 0.781 \\
\hline \multirow{3}{*}{$A D$ 'fruit and vegetable' } & Model 1 & -0.072 & 0.232 & -0.038 & 0.537 & -0.020 & 0.757 & -0.015 & 0.809 & 0.015 & 0.808 & 0.007 & 0.913 \\
\hline & Model 2 & 0.004 & 0.968 & 0.020 & 0.839 & -0.068 & 0.502 & 0.001 & 0.993 & -0.002 & 0.980 & -0.005 & 0.958 \\
\hline & Model 3 & -0.015 & 0.878 & -0.004 & 0.967 & -0.067 & 0.508 & -0.005 & 0.933 & 0.013 & 0.899 & -0.020 & 0.842 \\
\hline \multirow{3}{*}{ AD 'non-traditional Australian’ } & Model 1 & -0.046 & 0.448 & -0.025 & 0.684 & 0.033 & 0.612 & -0.041 & 0.510 & -0.014 & 0.817 & 0.061 & 0.337 \\
\hline & Model 2 & 0.106 & 0.278 & 0.056 & 0.571 & 0.061 & 0.551 & 0.047 & 0.636 & -0.033 & 0.743 & 0.173 & 0.090 \\
\hline & Model 3 & 0.083 & 0.386 & 0.013 & 0.899 & 0.059 & 0.566 & 0.035 & 0.726 & -0.035 & 0.732 & 0.159 & 0.124 \\
\hline \multirow[t]{3}{*}{ AD 'processed, high-sugar and high-fat' } & Model 1 & 0.038 & 0.532 & 0.039 & 0.522 & 0.113 & 0.075 & 0.046 & 0.455 & 0.011 & 0.855 & -0.001 & 0.982 \\
\hline & Model 2 & 0.031 & 0.673 & 0.027 & 0.716 & 0.132 & 0.091 & 0.005 & 0.947 & -0.030 & 0.690 & -0.019 & 0.808 \\
\hline & Model 3 & 0.031 & 0.670 & 0.031 & 0.683 & 0.133 & 0.089 & 0.017 & 0.826 & -0.006 & 0.939 & -0.009 & 0.910 \\
\hline \multirow[t]{3}{*}{ MAGE 'fruit, vegetable and non-processed' } & Model 1 & -0.104 & 0.116 & -0.057 & 0.396 & -0.024 & 0.730 & -0.033 & 0.625 & -0.006 & 0.925 & -0.010 & 0.884 \\
\hline & Model 2 & -0.048 & 0.540 & -0.016 & 0.870 & -0.046 & 0.643 & -0.014 & 0.884 & -0.037 & 0.698 & -0.044 & 0.654 \\
\hline & Model 3 & -0.074 & 0.425 & -0.015 & 0.873 & -0.067 & 0.501 & -0.027 & 0.783 & -0.040 & 0.678 & -0.047 & 0.640 \\
\hline \multirow[t]{3}{*}{ MAGE 'non-traditional Australian' } & Model 1 & -0.089 & 0.201 & -0.017 & 0.807 & 0.007 & 0.919 & -0.037 & 0.605 & 0.027 & 0.702 & 0.034 & 0.635 \\
\hline & Model 2 & -0.004 & 0.966 & 0.079 & 0.415 & 0.038 & 0.705 & 0.014 & 0.884 & 0.053 & 0.580 & 0.059 & 0.551 \\
\hline & Model 3 & -0.024 & 0.800 & 0.065 & 0.497 & 0.018 & 0.856 & -0.004 & 0.964 & 0.048 & 0.621 & 0.038 & 0.713 \\
\hline \multirow[t]{3}{*}{ MAGE 'processed, high-sugar and high-fat' } & Model 1 & -0.005 & 0.944 & 0.034 & 0.606 & 0.032 & 0.639 & 0.054 & 0.421 & 0.071 & 0.286 & 0.012 & 0.860 \\
\hline & Model 2 & -0.059 & 0.462 & 0.016 & 0.840 & -0.034 & 0.683 & 0.031 & 0.707 & 0.104 & 0.197 & 0.008 & 0.921 \\
\hline & Model 3 & -0.030 & 0.698 & 0.033 & 0.680 & -0.019 & 0.816 & 0.056 & 0.490 & 0.115 & 0.156 & 0.031 & 0.712 \\
\hline
\end{tabular}

CHD, childhood; EAD, early adulthood; AD, adulthood; MAGE, middle age.

'Model 1 adjusted for current diet, age, sex, years of education, smoking history, income level (parents' income for the two earlier life periods and current income for the two later life periods), English as native language and apoE $\varepsilon 4$ allele; model 2 adjusted for model 1 variables plus other past dietary patt
† Reversed $\beta$ sign for inhibition, so a higher score equals better performance. 
Table 4. Lifetime dietary factors as predictors of the accuracy-based constructs ${ }^{*}$

(Standardised regression weights $(\beta)$ with their $P$ values)

\begin{tabular}{|c|c|c|c|c|c|c|c|c|c|}
\hline \multirow[b]{2}{*}{ Lifetime dietary patterns } & & \multicolumn{2}{|c|}{ Working memory } & \multicolumn{2}{|c|}{ Retrieval fluency } & \multicolumn{2}{|c|}{ Short-term memory } & \multicolumn{2}{|c|}{ Reasoning } \\
\hline & & $\beta$ & $P$ & $\beta$ & $P$ & $\beta$ & $P$ & $\beta$ & $P$ \\
\hline \multirow[t]{3}{*}{ CHD 'vegetable and non-processed' } & Model 1 & -0.109 & 0.037 & -0.096 & 0.056 & -0.096 & 0.054 & -0.090 & 0.077 \\
\hline & Model 2 & -0.038 & 0.575 & -0.068 & 0.292 & -0.041 & 0.527 & -0.020 & 0.756 \\
\hline & Model 3 & 0.014 & 0.833 & -0.044 & 0.513 & 0.003 & 0.965 & 0.016 & 0.808 \\
\hline \multirow[t]{3}{*}{ CHD 'traditional Australian' } & Model 1 & -0.042 & 0.415 & 0.011 & 0.830 & -0.023 & 0.647 & -0.046 & 0.352 \\
\hline & Model 2 & 0.092 & 0.175 & 0.165 & 0.012 & 0.110 & 0.089 & 0.068 & 0.304 \\
\hline & Model 3 & 0.052 & 0.455 & 0.139 & 0.040 & 0.076 & 0.252 & 0.033 & 0.631 \\
\hline \multirow[t]{3}{*}{ CHD 'coffee and high-sugar, high-fat extras' } & Model 1 & -0.144 & 0.005 & -0.139 & 0.004 & -0.163 & 0.001 & -0.137 & 0.006 \\
\hline & Model 2 & -0.128 & 0.043 & -0.152 & 0.012 & -0.179 & 0.003 & -0.125 & 0.042 \\
\hline & Model 3 & -0.131 & 0.038 & -0.154 & 0.012 & -0.180 & 0.003 & -0.130 & 0.036 \\
\hline \multirow[t]{3}{*}{ EAD 'vegetable' } & Model 1 & -0.121 & 0.028 & -0.079 & 0.130 & -0.081 & 0.123 & -0.094 & 0.077 \\
\hline & Model 2 & -0.067 & 0.353 & -0.041 & 0.551 & -0.014 & 0.844 & -0.034 & 0.627 \\
\hline & Model 3 & -0.057 & 0.432 & -0.032 & 0.643 & -0.004 & 0.954 & -0.024 & 0.731 \\
\hline \multirow[t]{3}{*}{ EAD 'traditional Australian' } & Model 1 & -0.102 & 0.056 & -0.062 & 0.221 & -0.072 & 0.160 & -0.093 & 0.071 \\
\hline & Model 2 & -0.044 & 0.595 & 0.020 & 0.799 & 0.031 & 0.699 & -0.029 & 0.716 \\
\hline & Model 3 & -1.00 & 0.231 & -0.019 & 0.815 & -0.019 & 0.810 & -0.075 & 0.361 \\
\hline \multirow[t]{3}{*}{ EAD 'non-traditional Australian' } & Model 1 & -0.150 & 0.009 & -0.089 & 0.103 & -0.141 & 0.010 & -0.106 & 0.056 \\
\hline & Model 2 & -0.091 & 0.182 & -0.048 & 0.467 & -0.088 & 0.175 & -0.050 & 0.434 \\
\hline & Model 3 & -0.066 & 0.331 & -0.032 & 0.633 & -0.066 & 0.309 & -0.028 & 0.680 \\
\hline \multirow[t]{3}{*}{ AD 'fruit and vegetable' } & Model 1 & -0.093 & 0.102 & -0.101 & 0.059 & -0.096 & 0.074 & -0.107 & 0.050 \\
\hline & Model 2 & -0.032 & 0.719 & -0.148 & 0.082 & -0.093 & 0.275 & -0.115 & 0.188 \\
\hline & Model 3 & -0.039 & 0.660 & -0.150 & 0.080 & -0.096 & 0.257 & -0.120 & 0.172 \\
\hline \multirow[t]{3}{*}{ AD 'non-traditional Australian' } & Model 1 & -0.102 & 0.074 & -0.100 & 0.063 & -0.130 & 0.017 & -0.096 & 0.084 \\
\hline & Model 2 & 0.031 & 0.735 & -0.075 & 0.385 & -0.064 & 0.460 & -0.014 & 0.871 \\
\hline & Model 3 & 0.010 & 0.912 & -0.085 & 0.329 & -0.076 & 0.381 & -0.040 & 0.656 \\
\hline \multirow[t]{3}{*}{ AD 'processed, high-sugar and high-fat' } & Model 1 & 0.075 & 0.189 & 0.021 & 0.695 & 0.042 & 0.438 & 0.032 & 0.562 \\
\hline & Model 2 & 0.077 & 0.268 & 0.038 & 0.563 & 0.032 & 0.628 & 0.043 & 0.524 \\
\hline & Model 3 & 0.100 & 0.148 & 0.057 & 0.389 & 0.050 & 0.447 & 0.064 & 0.349 \\
\hline \multirow[t]{3}{*}{ MAGE 'fruit, vegetable and non-processed' } & Model 1 & -0.130 & 0.035 & -0.046 & 0.431 & -0.090 & 0.127 & -0.093 & $0 \cdot 120$ \\
\hline & Model 2 & -0.076 & 0.387 & 0.042 & 0.611 & -0.019 & 0.822 & -0.028 & 0.745 \\
\hline & Model 3 & -0.065 & 0.457 & 0.053 & 0.531 & -0.010 & 0.904 & -0.018 & 0.836 \\
\hline \multirow[t]{3}{*}{ MAGE 'non-traditional Australian' } & Model 1 & -0.061 & 0.349 & -0.029 & 0.640 & -0.064 & 0.302 & -0.042 & 0.503 \\
\hline & Model 2 & 0.107 & 0.224 & 0.090 & 0.283 & 0.070 & 0.401 & 0.099 & 0.248 \\
\hline & Model 3 & 0.105 & 0.230 & 0.081 & 0.339 & 0.056 & 0.502 & 0.096 & 0.266 \\
\hline \multirow[t]{3}{*}{ MAGE 'processed, high-sugar and high-fat' } & Model 1 & 0.069 & 0.262 & 0.007 & 0.903 & 0.050 & 0.396 & 0.042 & 0.476 \\
\hline & Model 2 & 0.071 & 0.338 & 0.012 & 0.862 & 0.058 & 0.410 & 0.069 & 0.341 \\
\hline & Model 3 & 0.088 & 0.229 & 0.026 & 0.715 & 0.078 & 0.263 & 0.080 & 0.265 \\
\hline
\end{tabular}

CHD, childhood; EAD, early adulthood; AD, adulthood; MAGE, middle age.

* Model 1 adjusted for current diet, age, sex, years of education, smoking history, income level (parents' income for the two earlier life periods and current income for the two later life periods), English as native language and apoE $\varepsilon 4$ allele; model 2 adjusted for model 1 variables plus other past dietary patterns; model 3 adjusted for model 1 and model 2 variables plus mechanistic health-related variables.

time during the years of the Great Depression, World War Two and the early post-war years. During this period, there were food shortages and food rationing; the availability of animal products was limited and reliance on garden-grown vegetables was promoted by the government to combat food shortages $^{(44)}$. The childhood 'vegetable and non-processed' pattern could be a marker for early-life nutritional deprivation that was not captured by adjusting for parental income levels, given that both rich and poor alike were subject to limited food availability during these years ${ }^{(45)}$. This pattern was defined by garden-grown vegetables, legumes and an absence of animal products with the exception of oily fish. (Given the era of recall, the oily fish consumed is likely to have been tinned sardines or salmon; fish consumption at that time was relatively low in Australia compared with other nations and the fish industry was in its infancy) $)^{(46)}$. The 'vegetable and non-processed' pattern was negatively associated with all cognitive constructs, and after adjustment, it remained a negative predictor of simple/choice reaction time.
Food shortages during the war years did not necessarily have an equal impact across the population, with those living in some farming communities having greater access to a wider range, and possibly a greater quantity, of food ${ }^{(47)}$, as would have younger participants whose childhood dietary recall period extended into the 1950s when food production and supply had recovered from war-time austerity measures ${ }^{(48)}$. The childhood 'traditional Australian' pattern was defined by a greater variety of foods, and a higher score on this pattern may represent more adequate nutritional intake during childhood in comparison with the more frugal 'vegetable and non-processed' pattern. In adjusted models, this pattern positively predicted perceptual speed and retrieval fluency, although for perceptual speed, the association did not remain significant once the mechanistic health-related variables were controlled for.

Consumption of a processed pattern in childhood contributes to childhood obesity that has been shown to predict higher blood pressure in adulthood ${ }^{(49)}$. Hypertension is a 
well-established risk factor for cognitive decline and dementia, and has been demonstrated to predict vascular brain injury in adults as early as the fourth decade ${ }^{(50)}$. Hypertension during this particular life period, therefore, provides a potential pathway by which a childhood diet high in fat and sugary foods may have an impact on older-age cognitive performance. However, it is interesting that when systolic blood pressure and hypertensive medications were adjusted for in the final model, the associations were not attenuated. It is possible that later lifestyle modification may have reduced adulthood hypertension, so it did not continue into older age. Alternatively, higher consumption of a 'processed' (high fat and sugar content) pattern in early childhood has been associated with lower overall intelligence quotient, and in particular verbal intelligence quotient, assessed at 8.5 years ${ }^{(51)}$. Early-life childhood intelligence measures strongly predict older-age cognitive functioning ${ }^{(17)}$ and for participants in the present study, greater consumption of the 'coffee and high-sugar, high-fat extra' pattern in childhood may have had a negative impact on cognitive performance via its influence on the development of childhood cognitive ability.

A comparison with the findings of others is difficult because very few studies have been able to test the associations between dietary patterns from the relatively distant past (greater than a decade previously) and late-life cognitive outcomes. Mid-life consumption of a healthy pattern in the SU.VI.MAX 2 cohort has been shown to be positively associated with global cognitive functioning in addition to verbal memory 13 years later $^{(23)}$. Unexpectedly, in the present study, there were no comparable associations between the dietary pattern scores for middle age and any of the cognitive constructs in the adjusted models. It was considered possible that in these models, adjusting for current intake suppressed associations, given the previously demonstrated strong relationship between current and mid-life dietary patterns in this sample ${ }^{(26)}$. Supplementary analyses, however, demonstrated that this was not the case; when current diet was excluded, no further associations emerged. It could be argued that dietary patterns extracted from recalled intake over such a long period are of questionable validity; however, the LDQ was designed around the cognitive strategies known to underpin long-term dietary recalls, such as the use of generic food memories rather than detailed quantitative information ${ }^{(52)}$ and life-period-cue questions to contextualise dietary memories ${ }^{(53)}$. In addition, plausible associations between the lifetime dietary patterns and both demographic and cardiovascular variables have been demonstrated previously in this sample ${ }^{(26)}$, which supports the validity of both long-term dietary recall and the dietary patterns extracted.

One of the main confounders of past diet memory is the impact of current diet on the recall process ${ }^{(54)}$. The adjustment for current diet in all models was one of the strengths of the present study; this ensured that associations between the past dietary factors and cognitive performance were not driven by current intake.

An inevitable limitation to the study design is the problem of controlling for unmeasured life period-specific covariates that potentially would have an impact on the findings. Despite the extensive range of theoretically relevant demographic, lifestyle and health-related variables included in the analyses, it is acknowledged that confounding by unmeasured life periodspecific covariates cannot be discounted. The determinants of dietary choice and behaviour are embedded within complex personal and social systems ${ }^{(55)}$. Given the time period across which dietary intake was being measured, covariate control could not be comprehensive. This is particularly relevant given the associations that we have reported between dietary patterns consumed in childhood and cognition in later life. It would be of interest to explore these associations further by including additional appropriate early-life autobiographical information from participants in analyses.

Cross-sectional designs investigating the impact of current dietary exposures on the measures of cognition are limited by the possibility of reverse causation. Preference for sweet foods may be influenced by changes in brain glucose metabolism that occur in those that develop dementia ${ }^{(56)}$ and such changes may determine dietary choices, rather than dietary intake making an impact on cognitive outcomes. Although technically cross-sectional, the present study assessed dietary intake from earlier decades preceding the periods when such changes are likely. This adds weight to the causal direction of dietary pattern predictions of cognitive measures. Reverse causation is also possible because early-life intellectual ability has an impact on later food choice ${ }^{(57)}$. However, this was unlikely in the present study because the associations between dietary patterns and later-life cognitive performance were all from the childhood period, when individuals' dietary choices would have been largely determined by their families, although the influence of parental intellectual ability on family diet cannot be discounted.

The extensive test battery available to assess multiple cognitive domains in this sample was one of the strengths of the present study. Constructs were measured by two or more tests that increased reliability, and the battery overall was designed specifically to be sensitive to the effects of ageing on cognitive abilities ${ }^{(27)}$.

This is the first known study to examine the associations between recalled dietary patterns from multiple life periods and older-age cognitive performance; replication of this approach is necessary and results from a sample of convenience cannot be generalised to other populations. Moreover, it is acknowledged that the LDQ from which the lifetime dietary patterns were derived is a new measure and further testing of the questionnaire's validity is desirable. Investigation of the associations between recalled dietary patterns and longitudinal cognitive change is also warranted. Additionally, assessing long-term dietary intake and late-life cognition performance in culturally varied cohorts would be of interest.

The finding that dietary patterns from across the lifetime significantly predicted cognitive performance over and above its associations with current diet supports the relevance of early-life dietary exposures to later-life cognitive outcomes. After adjustment for the variance shared between the lifetime dietary patterns, childhood was the only life period for which dietary patterns remained to be significant predictors 
of later-life cognitive performance. These preliminary findings are relevant in terms of identifying childhood as a 'critical period' for intervention to minimise the possibility of laterlife cognitive deficits.

\section{Acknowledgements}

The authors gratefully acknowledge the contribution of the EPOCH research team and thank the EPOCH participants for their commitment and participation.

The EPOCH trial was supported by the University of Adelaide and the CSIRO Animal, Food and Health Sciences Brailsford Robertson Award (to V. D., T. N. and C. W.) and a National Health and Medical Research Project Grant (no. 578800; to V. D., T. N. and C. W.). D. E. H. was supported by a PhD scholarship jointly funded by the Faculty of Health Sciences at the University of Adelaide, South Australia, and the CSIRO Animal Food and Health Sciences.

The funders had no role in the design, analysis or writing of this article.

The authors' contributions were as follows: V. D., T. N., C. W. and D. E. H. designed the research; D. E. H. and V. D. conducted the research and performed the statistical analysis; D. E. H. wrote the paper. All authors read and approved the final manuscript.

There are no conflicts of interest.

\section{References}

1. Brookmeyer R, Johnson E, Ziegler-Graham K, et al. (2007) Forecasting the global burden of Alzheimer's disease. Alzheimers Demen 3, 186-191.

2. Gómez-Pinilla F (2008) Brain foods: the effects of nutrients on brain function. Nat Rev Neurosci 9, 568-578.

3. Spiro A \& Brady CB (2011) Integrating health into cognitive aging: toward a preventive cognitive neuroscience of aging. J Gerontol B Psychol Sci Soc Sci 66B, Suppl. 1, i17-i25.

4. Gu Y \& Scarmeas N (2011) Dietary patterns in Alzheimers disease and cognitive aging. Curr Alzheimer Res 8, 510-519.

5. Scarmeas N, Stern Y, Tang M, et al. (2006) Mediterranean diet and risk for Alzheimer's disease. Ann Neurol 59, 912-921.

6. Scarmeas N, Stern Y, Mayeux R, et al. (2009) Mediterranean diet and mild cognitive impairment. Arch Neurol 66, $216-225$.

7. Tangney CC, Kwasny MJ, Li H, et al. (2011) Adherence to a Mediterranean-type dietary pattern and cognitive decline in a community population. Am J Clin Nutr 93, 601-607.

8. Barberger-Gateau P, Raffaitin C, Letenneur L, et al. (2007) Dietary patterns and risk of dementia: the three city cohort study. Neurology 69, 1921-1930.

9. Gu Y, Nieves JW, Stern Y, et al. (2010) Food combination and Alzheimer disease risk: a protective diet. Arch Neurol 67, E2-E8.

10. Wengreen HJ, Neilson C, Munger R, et al. (2009) Diet quality is associated with better cognitive test performance among aging men and women. J Nutr 139, 1944-1949.

11. Samieri C, Jutand MA, Feart C, et al. (2008) Dietary patterns derived by hybrid clustering method in older people: association with cognition, mood, and self-rated health. J Am Diet Assoc 108, 1461-1471.

12. Akbaraly TN, Singh-Manoux A, Marmot MG, et al. (2009) Education attenuates the association between dietary patterns and cognition. Dement Geriatr Cogn Disord 27, $147-154$.

13. Valls-Pedret C, Lamuela-Raventós RM, Medina-Remón A, et al. (2012) Polyphenol-rich foods in the Mediterranean diet are associated with better cognitive function in elderly subjects at high cardiovascular risk. J Alzheimers Dis 29, 773-782.

14. Nurk E, Refsuma H, Drevona C, et al. (2010) Cognitive performance among the elderly in relation to the intake of plant foods. The Hordaland Health Study. Br J Nutr 104, 1190-1201.

15. Samieri C, Okereke OI \& Devore EE, et al. (2013) Long-term adherence to the Mediterranean diet is associated with overall cognitive status, but not cognitive decline, in women. J Nutr 143, 493-499.

16. Torres $\mathrm{S}$, Lautenschlager $\mathrm{N}$, Wattanapenpaiboon $\mathrm{N}$, et al. (2012) Dietary patterns are associated with cognition among older people with mild cognitive impairment. Nutrients 4, 1542-1551.

17. Deary IJ, Whiteman MC, Starr JM, et al. (2004) The impact of childhood intelligence in later life: following up the Scottish mental surveys of 1932 and 1947. J Pers Soc Psychol 86, $130-147$.

18. Salthouse TA (2009) When does age-related cognitive decline begin? Neurobiol Aging 30, 507-143, 493-499.

19. Sperling RA, Aisen PS, Beckett LA, et al. (2011) Toward defining the preclinical stages of Alzheimer's disease: recommendations from the National Institute on AgingAlzheimer's Association workgroups on diagnostic guidelines for Alzheimer's disease. Alzheimers Demen 7, 280-292.

20. Xiong C, Roe CM, Buckles V, et al. (2011) Role of family history for Alzheimer biomarker abnormalities in the adult children study. Arch Neurol 68, 1313-1319.

21. Benton D (2010) Neurodevelopment and neurodegeneration: are there critical stages for nutritional intervention? Nutr Rev 68, S6-S10.

22. Kesse-Guyot E, Amieva H, Castetbon K, et al. (2011) Adherence to nutritional recommendations and subsequent cognitive performance: findings from the prospective Supplementation with Antioxidant Vitamins and Minerals 2 (SU.VI.MAX 2) study. Am J Clin Nutr 93, 200-210.

23. Kesse-Guyot E, Andreeva VA, Jeandel C, et al. (2012) A healthy dietary pattern at midlife is associated with subsequent cognitive performance. J Nutr 142, 909-915.

24. Richards M \& Deary I (2005) A life course approach to cognitive reserve: a model for cognitive aging and development? Ann Neurol 58, 617-622.

25. Hosking D, Danthiir V, Nettelbeck T, et al. (2011) Assessing lifetime diet: reproducibility of a self-administered, nonquantitative FFQ. Public Heath Nutr 14, 801-808.

26. Hosking D \& Danthiir V (2013) Retrospective lifetime dietary patterns are associated with demographic and cardiovascular health variables in an older community-dwelling Australian population. Br J Nutr 110, 2069-2083.

27. Danthiir V, Burns NR, Nettelbeck T, et al. (2011) The older people, omega-3, and cognitive health (EPOCH) trial design and methodology: a randomised, double-blind, controlled trial investigating the effect of long-chain omega-3 fatty acids on cognitive ageing and wellbeing in cognitively healthy older adults. Nutr J 10, 1-36.

28. Newkirk LA, Kim JM, Thompson JM, et al. (2004) Validation of a 26-point telephone version of the Mini-Mental State Examination. J Geriatr Psychiatry Neurol 17, 81-87.

29. Muthén LK \& Muthén BO (2007) Mplus User's Guide, 5th ed. Los Angeles, CA: Muthén \& Muthén. 
30. Hu FB (2002) Dietary pattern analysis: a new direction in nutritional epidemiology. Curr Opin Lipidol 13, 3-9.

31. Newby PK \& Tucker KL (2004) Empirically derived eating patterns using factor or cluster analysis: a review. Nutr Rev 62, 177-203.

32. Moeller SM, Reedy J, Millen AE, et al. (2007) Dietary patterns: challenges and opportunities in dietary patterns research: an experimental biology workshop. J Am Diet Assoc 107, $1233-1239$

33. Danthiir V, Wilhelm O \& Roberts RD (2012) Further evidence for a multifaceted model of mental speed: factor structure and validity of computerized measures. Learn Individ Differen 22, 324-335.

34. Salthouse TA (1996) The processing-speed theory of adult age differences in cognition. Psychol Rev 103, 403-428.

35. Radloff LS (1977) The CES-D scale: a self report depression scale for research in the general population. Appl Psychol Measure 1, 385-401.

36. Dipietro L, Caspersen CJ, Ostfeld AM, et al. (1993) A survey for assessing physical-activity among older adults. Med Sci Sports Exerc 25, 628-642.

37. Friedenreich CM, Slimani N \& Riboli E (1992) Measurement of past diet: review of previous and proposed methods. Epidemiol Rev 14, 177-196.

38. Giles GG \& Ireland PD (1996) Dietary Questionnaire for Epidemiological Studies (Version 2). Melbourne: Cancer Council Victoria.

39. Dempster AP, Laird NM \& Rubin DB (1977) Maximum likelihood from incomplete data via the EM algorithm. $J$ Roy Stat Soc 39, 1-38.

40. Faul F, Erdfelder E, Lang A-G, et al. (2007) G*Power 3: a flexible statistical power analysis program for the social, behavioral, and biomedical sciences. Behav Res Methods 39, $175-191$.

41. Benton D (2008) The influence of children's diet on their cognition and behaviour. Eur J Nutr 47, Suppl. 3, 25-37.

42. Dagnelie PC \& van Staveren WA (1994) Macrobiotic nutrition and child health: results of a population-based, mixedlongitudinal cohort study in The Netherlands. Am J Clin Nutr 59, Suppl. 5, 1187S-1196S.

43. Heys M, Jiang C, Schooling CM, et al. (2010) Is childhood meat eating associated with better later adulthood cognition in a developing population? Eur J Epidemiol 25, 507-516.
44. Gaynor A (2006) Harvest of the Suburbs: An Environmental History of Growing Food in Australian Cities. Crawley, WA: University of Western Australia Press.

45. Collingham L (2012) World War Two and the Battle for Food. New York: Pengu Press.

46. ABS (1941) Official Year Book of the Commonwealth of Australia. Canberra: Commonwealth of Australia.

47. Gregory J (editor) (1996) On the Home Front: Western Australia and World War II. Nedlands, WA: University of Western Australia Press.

48. Truswell AS \& Wahlqvist ML (1988) Food Habits in Australia: The First Deakin/Syndey Universities Symposium on Australian Nutrition, 1st ed. North Balwyn: Renè Gordon Private Limited.

49. Lawlor DA \& Smith GD (2005) Early life determinants of adult blood pressure. Curr Opin Nephrol Hypertens 14 259-264.

50. Maillard P, Seshadri S, Beiser A, et al. (2012) Effects of systolic blood pressure on white-matter integrity in young adults in the Framingham Heart Study: a cross-sectional study. Lancet Neurol 11, 1039-1047.

51. Northstone K, Joinson C, Emmett P, et al. (2012) Are dietary patterns in childhood associated with IQ at 8 years of age? A population-based cohort study. J Epidemiol Community Health 66, 624-628.

52. Smith A (1993) Cognitive psychological issues of relevance to the validity of dietary reports. Eur J Clin Nutr $\mathbf{4 7}$, Suppl. 2, S6-S18.

53. Friedenreich CM (1994) Improving long-term recall in epidemiologic studies. Epidemiology 5, 1-4.

54. Wu ML, Whittemore AS \& Jung DL (1988) Errors in reported dietary intakes: long-term recall. Am $J$ Epidemiol 128, $1137-1145$.

55. Shepherd R (1999) Social determinants of food choice. Proc Nutr Soc 58, 807-812.

56. Talbot K, Wang H-Y, Kazi H, et al. (2012) Demonstrated brain insulin resistance in Alzheimer's disease patients is associated with IGF-1 resistance, IRS-1 dysregulation, and cognitive decline. J Clin Invest 122, 1316-1338.

57. Gale CR, Deary IJ, Schoon I, et al. (2007) IQ in childhood and vegetarianism in adulthood: 1970 British cohort study. BMJ 334, 245. 